\title{
Phenothiazine and Carbazole Substituted Pyrene Based Electroluminescent Organic Semiconductors for OLED Devices
}

\author{
Jagadish K. Salunke, ${ }^{\text {a, b}}$ F. L. Wong, ${ }^{\mathrm{c}}$ Krishna Feron, ${ }^{\mathrm{d}}$ Sergei Manzhos, ${ }^{\mathrm{e}}$ Ming Fai Lo, ${ }^{\mathrm{c}}$ Durgaprasad

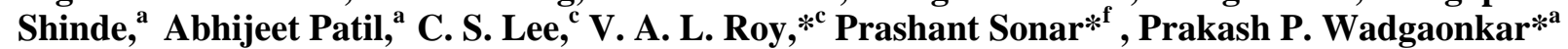 \\ ${ }_{5}$ Received (in $\left.X X X, X X X\right) X_{\text {th }} X X X X X X X X X 20 X X$, Accepted $X$ th $X X X X X X X X X 20 X X$ \\ DOI: 10.1039/b000000x
}

Due to the easy availability, low cost and opportunities for exploiting reactions of bromo substituents, 1, 3, 6, 8tetrabromopyrene has attracted major attention in organic 10 electronics community for designing and constructing novel classes of pyrene based organic semiconducting functional materials. In the present work, 1, 3, 6, 8-tetrabromo pyrene was transformed into corresponding tetrasubstituted carbazole and phenothiazine derivatives using the classical Suzuki coupling 15 reaction. These newly synthesized materials with carbazole substituent (PY-CA) and phenothiazine substituent (PY-PH) were characterised thoroughly and were successfully used as an active light-emitting layer in organic light emitting diodes which resulted in blue and green emission with promising device 20 performance. PY-CA exhibited maximum brightness around $2500 \mathrm{~cd} / \mathrm{m}^{2}$ and power efficiency of $1.5 \mathrm{~lm} / \mathrm{W}$ while PY-PH exhibited $2116 \mathrm{~cd} / \mathrm{m}^{2}$ brightness and power efficiency $0.45 \mathrm{~lm} / \mathrm{W}$ respectively.

\section{Introduction}

25 Since the discovery of organic light emitting diodes (OLEDs), numerous classes of light emitting organic semiconductors have been designed and developed and these efforts are still continuing in order to find materials that are easy to synthesize and exhibit improved solution processability and high efficiency. ${ }^{1-3}$ The ${ }_{30}$ OLED technology has been used successfully for flat panel display and solid-state lighting applications. ${ }^{4,5}$ Still there is a demand for the development of efficient pure red, blue, and green light emitting materials for OLEDs. Blue light emitting materials are also one of the important key elements for fabricating white ${ }_{35}$ OLED devices. Conjugated building blocks such as antracene, ${ }^{6}$ pyrene, ${ }^{7}$ phenothiazine ${ }^{8}$ and carbazole ${ }^{9}$ have been successfully used for designing and synthesizing light emitting active layers for OLED devices. However, current OLEDs still have some problems to get pure strong emission with lower power 40 consumption which is determined by driving voltage and efficiency of the devices. Low driving voltage and high efficiency are required to reduce the power consumption of OLEDs. ${ }^{10}$ In addition to the above issues, the electroluminescence properties of blue-emitting materials remain challenging, ${ }^{11}$ particularly in

45 terms of easy availability, lower cost, efficiency, stability, and color purity. Thus, it is very important to explore the new class of blue materials using various synthetic methodologies and potential starting precursor building blocks. Among such potential building blocks, pyrene conjugated system have 50 attracted considerable interest in the designing of small organic molecules for different applications including OLEDs ${ }^{12-15}$ and organic field effect transistors (OFETs) ${ }^{16-19}$ due to its fused four aromatic condensed planar structure. Pyrene is a promising chromophore with higher fluorescent quantum yield which makes 55 it an attractive candidate for designing functional materials for fluorescent probes and labeling experiments. Recently, N, N-di-pmethoxyphenylamine-substituted pyrene has been successfully used as a hole transporting materials for perovskite based solar cells with high efficiency. ${ }^{20}$ These examples clearly reveal that ${ }_{60}$ pyrene is a versatile conjugated building block and can be used for designing a variety of conjugated functional materials. Pyrene posseses excellent thermal \& chemical stability but on its own is not a good candidate for light emitting devices due to its excimer emission tendency which diminishes the fluorescence ${ }_{65}$ efficiency. ${ }^{21,22}$ Nonetheless, this limitation of pyrene has been overcome by introducing bulky groups with long alkyl chains which enhances fluorescence quantum efficiency in OLEDs and also reduces the aggregation of the final material. ${ }^{23}$ Over the last few years, our group has been exploring 1, 3, 6, 8 substituted 70 pyrene based conjugated molecular functional materials for organic electronic devices. Initially, we reported a series of starshaped organic semiconductors using bithiophene, phenylene, thienothiophene, and benzothiadiazole-thiophene chromophores. Among them, 1, 3, 6, 8-tetrakis (4-butoxyphenyl) pyrene, was 75 used as the active emitting layer in simple solution-processed OLEDs with deep blue emission $(\mathrm{CIE}=0.15,0.18)$ and maximum efficiencies and brightness levels of $2.56 \mathrm{~cd} / \mathrm{A}$ and $5000 \mathrm{~cd} / \mathrm{m}^{2}$, respectively. ${ }^{24}$ In our second attempt, we synthesized single, double and triple bond incorporated three pyrene cored small 80 conjugated molecules with octyloxy naphthalene conjugated substituent decorated at 1, 3, 6, 8 position of pyrene via Suzuki, Heck and Sonogashira coupling reactions, respectively. The effects of single, double and triple bonds on their optical, electrochemical, and thermal properties were studied in detail and 85 all these materials were used successfully in OLEDs. ${ }^{25}$ In the present work, we wish to report design, synthesis and characterization of two new compounds 1, 3, 6, 8-tetrakis(9-(4- 
methoxyphenyl)-9H-carbazol-3-yl)pyrene (PY-CA) and 1, 3, 6, 8-tetrakis(10-(4-methoxyphenyl)-10H-phenothiazin-3-yl)pyrene

(PY-PH). Although the carbazole and phenothiazine combination have been reported as an efficient deep blue and green emitting 5 material in OLEDs earlier ${ }^{26,27}$ but so far there is no report in the literature about using them in the form of tetra-functionalized pyrene derivatives for any device application. Our results reveal that introduction of carbazole and phenothiazine unit on tetrabromopyrene core is the effective way to design wide band 10 gap electroluminescent materials. Upon using these materials in OLED devices, carbazole substituted material exhibits blue emission with electroluminescent peak at $493 \mathrm{~nm}$ whereas phenothiazine substituted compound demonstrates green emission with electroluminescent peak at $540 \mathrm{~nm}$. The highest 15 brightness for carbazole and phenothiazine substituted pyrene was measured in OLED devices and which was found around $2500 \mathrm{~cd} / \mathrm{m}^{2}$ and $2116 \mathrm{~cd} / \mathrm{m}^{2}$ respectively. The reported OLED data clearly indicates that these classes of functional materials hold a great promise for designing future cost effective and 20 efficient light emitting materials for OLED devices.

\section{Experimental}

All chemicals (palladium catalysts, bis (pinacolato) diboron, $\mathrm{N}$ bromosuccinimide, 4-iodoanisole, potassium acetate and 1, 3, 6, 25 8-tetrabromopyrene) and solvents were purchased from Aldrich and were used without further purification. All the reactions were carried out using round bottom flask or Schlenk tube under an argon or nitrogen atmosphere in anhydrous solvents. ${ }^{1} \mathrm{H}$ and ${ }^{13} \mathrm{C}$ NMR spectra were recorded in $\mathrm{CDCl}_{3}$ on Bruker $\mathrm{AC}$ 30 spectrometer operating at $400 \mathrm{MHz}$ for ${ }^{1} \mathrm{H}$ and $100 \mathrm{MHz}$ for ${ }^{13} \mathrm{C}$. The chemical shifts are referenced to tetramethylsilane (TMS). Matrix assisted laser desorption/ionization time-of flight (MALDI-TOF) mass spectra were obtained on a Bruker Autoflex TOF/TOF instrument using dithranol as a matrix. Melting points 35 were recorded by open capillary method. UV-Vis and photoluminescence (PL) spectra were recorded on Jasco V-570, and Cary Eclipse Fluorescence spectrofluorometer, respectively using chloroform as a solvent.

40 Synthesis of 9H-carbazole-9-(4-methoxyphenyl) (2): Carbazole (2 g, $50 \mathrm{mmol})$, 4-iodoanisole (2.8 g, $60 \mathrm{mmol})$, copper powder $(0.536 \mathrm{~g}, 50 \mathrm{mmol})$, potassium carbonate $(2.7 \mathrm{~g}, 100 \mathrm{mmol})$ and triethylene glycol dimethyl ether (TEGDME) (30 mL) were added into Schlenk tube and the mixture was stirred under the 45 argon atmosphere at $180{ }^{\circ} \mathrm{C}$ for $24 \mathrm{~h}$. The reaction mixture was cooled to room temperature, filtered and poured into $500 \mathrm{~mL}$ of ice cold water. The white precipitate was collected by filtration. Recrystallization from $100 \mathrm{~mL}$ of methanol gave white crystalline solid $(2,27 \mathrm{~g}, 70 \%$ yield $)$ : $\left(\mathrm{mp}=153-154{ }^{\circ} \mathrm{C}\right.$; lit. $\left.154-155^{\circ} \mathrm{C}\right)$ ${ }_{50}{ }^{28} .{ }^{1} \mathrm{H} \mathrm{NMR}\left(400 \mathrm{MHz}, \mathrm{CDCl}_{3}\right) \delta=8.14-8.01(\mathrm{~m}, 2 \mathrm{H}), 7.45-$ $7.14(\mathrm{~m}, 8 \mathrm{H}), 7.08-6.98(\mathrm{~m}, 2 \mathrm{H}), 7.03$ (d, J = 9.0 Hz, 9 H), 3.84 $(\mathrm{s}, 3 \mathrm{H}) .{ }^{13} \mathrm{C} \mathrm{NMR}\left(100 \mathrm{MHz}, \mathrm{CDCl}_{3}\right) \delta=141.3,128.5,125.8$, 123.0, 119.9, 115.0, 109.6, 55.6.

${ }_{55}$ Synthesis of 3-bromo-9-(4-methoxyphenyl)-9H-carbazole (3): 9H-Carbazole-9-(4-methoxyphenyl) (5 g, $10 \mathrm{mmol})$ was added into two necked round bottom flask containing chloroform (200 $\mathrm{mL})$. After purging the reaction mixture for half an hour, $\mathrm{N}$ bromosuccinimide $(3,58 \mathrm{~g}, 12 \mathrm{mmol})$ was added and the reaction 60 mixture was stirred for $12 \mathrm{hr}$ at room temperature. The solution was poured into $500 \mathrm{~mL}$ of ice cold water and organic layer was extracted with $100 \mathrm{~mL}$ of dichloromethane. The combined organic layer was washed with $200 \mathrm{~mL}$ of water, dried over anhydrous sodium sulfate and filtered. Removal of solvent on a 65 rotary evaporator afforded a crude product which was then chromatographed on silica with petroleum ether as an eluent to obtain title compound $\left(5.51 \mathrm{~g}, 80 \%\right.$ yield), as a white solid. ${ }^{1} \mathrm{H}$ NMR (400 MHz, $\left.\mathrm{CDCl}_{3}\right) \delta=8.29(\mathrm{~d}, \mathrm{~J}=1.5 \mathrm{~Hz}, 1 \mathrm{H}), 8.12(\mathrm{~d}, \mathrm{~J}$ $=7.8 \mathrm{~Hz}, 1 \mathrm{H}), 7.60-7.41(\mathrm{~m}, 4 \mathrm{H}), 7.41-7.27(\mathrm{~m}, 2 \mathrm{H}), 7.26-$ $707.09(\mathrm{~m}, 3 \mathrm{H}), 3.94$ (s, $3 \mathrm{H}) \cdot{ }^{13} \mathrm{C}$ NMR $\left(100 \mathrm{MHz}, \mathrm{CDCl}_{3}\right) \delta=$ $159.1,140.9,129.8,127.1,123.0,122.1,120.3,115.2,112.5$, 111.2, 110.0, 77.1, 55.6.

Synthesis of 9-(4-methoxyphenyl)-3-(4,4,5,5-tetramethyl75 1,3,2-dioxaborolan-2-yl)-9H-carbazole (4): 3-Bromo-9-(4methoxyphenyl)-9H-carbazole $(2 \mathrm{~g}, \quad 1 \quad \mathrm{mmol})$, bis(pinacolato)diboron (1.4 g, $1.2 \mathrm{mmol}), \mathrm{PdCl}_{2}$ (dppf) (418 mg, $0.1 \mathrm{mmol})$ and potassium acetate $(1.6 \mathrm{~g}, 3 \mathrm{mmol})$ were added in Schlenk tube under argon flow and then evacuated for half an 80 hour. Under an argon flow, anhydrous dioxane $(25 \mathrm{~mL})$ was added to the reaction mixture. The solution was stirred at room temperature for $30 \mathrm{~min}$, and then at $80{ }^{\circ} \mathrm{C}$ for $24 \mathrm{~h}$. The reaction mixture was quenched by addition of ice-cold water $(250 \mathrm{~mL})$ and then extracted with dichloromethane $(250 \mathrm{~mL})$. The 85 dichloromethane solution was washed with water, dried over anhydrous sodium sulfate and filtered. Removal of solvent on a rotary evaporator afforded a crude product which was chromatographed on neutral alumina with $2 \%$ dichloromethane in petroleum ether as an eluent to obtain title compound (1.47 g, 65 ${ }_{90} \%$ yield), as a yellow solid. ${ }^{1} \mathrm{H}$ NMR (400 MHz, $\left.\mathrm{CDCl}_{3}\right) \delta=8.63$ (s, $3 \mathrm{H}), 8.29-8.08(\mathrm{~m}, 3 \mathrm{H}), 7.84$ (d, J = 8.2 Hz, $3 \mathrm{H}), 7.53$ $7.20(\mathrm{~m}, 19 \mathrm{H}), 7.10(\mathrm{~d}, \mathrm{~J}=8.5 \mathrm{~Hz}, 6 \mathrm{H}), 3.90(\mathrm{~d}, \mathrm{~J}=0.6 \mathrm{~Hz}, 3$ $\mathrm{H}), 1.39$ (s, $12 \mathrm{H}) .{ }^{13} \mathrm{C} \mathrm{NMR}\left(100 \mathrm{MHz}, \mathrm{CDCl}_{3}\right) \delta=159.5,142.1$, 132.9, 130.6, 128.7, 126.5, 123.7, 121.2, 115.7, 110.0, 84.2, 56.2, 9525.5

Synthesis of 1,3,6,8-tetrakis(9-(4-methoxyphenyl)-9Hcarbazol-3-yl)pyrene (PY-CA): 1,3,6,8-Tetrabromopyrene $(0.5$ g, $1 \mathrm{mmol}$ ), 9-(4-methoxyphenyl)-3-(4,4,5,5-tetramethyl-1,3,2100 dioxaborolan-2-yl)-9H-carbazole (2.31 g, $6 \mathrm{mmol}), 2 \mathrm{M} \mathrm{K}_{2} \mathrm{CO}_{3}(5$ $\mathrm{mL})$ and $\mathrm{Pd}\left(\mathrm{PPh}_{3}\right)_{4}(0.111 \mathrm{~g}, 0.1 \mathrm{mmol})$ were added in Schlenk tube under argon flow. The flask was evacuated and refilled with argon three times and then anhydrous THF $(25 \mathrm{~mL})$ was added into the flask and reaction mixture was stirred at $80{ }^{\circ} \mathrm{C}$ for $48 \mathrm{~h}$. 105 The reaction mixture was extracted with dichloromethane $(250$ $\mathrm{mL})$ and washed with water $(500 \mathrm{~mL})$ and dried over anhydrous magnesium sulphate. Removal of solvent on rotary evaporator afforded a crude product which was then purified using silica gel column chromatography with $2 \%$ dichloromethane in petroleum 110 ether as an eluent to obtain title compound PY-CA (0.969 g, 78\% yield), as a green solid. 1H NMR (400 MHz , $\delta=8.54(\mathrm{~s}, 4 \mathrm{H})$, $8.38(\mathrm{~s}, 10 \mathrm{H}), 7.82(\mathrm{~d}, \mathrm{~J}=1.5 \mathrm{~Hz}, 4 \mathrm{H}), 7.63-7.50(\mathrm{~m}, 11 \mathrm{H})$, 
7.49 - 7.38 (m, 9 H), 7.28 (s, $4 \mathrm{H}), 7.21-7.13$ (m, $8 \mathrm{H}), 3.96$ (s, $12 \mathrm{H}) .13 \mathrm{C} \mathrm{NMR}\left(100 \mathrm{MHz}, \mathrm{CDCl}_{3}\right) \delta=158.9,141.3,137.8$, 133.0, 129.6, 126.6, 123.0, 120.1, 115.1, 109.7, 55.6. MALDITOF: calculated 1288.00 , found 1287.73 .

${ }_{5}$ Synthesis of 10-(4-methoxyphenyl)-10H-phenothiazine (6): A mixture of phenothiazine $(2 \mathrm{~g}, 50 \mathrm{mmol})$, 4-iodoanisole $(3.36 \mathrm{~g}$, $60 \mathrm{mmol})$, copper powder $(0.754 \mathrm{~g}, 50 \mathrm{mmol})$, potassium carbonate $(3.30 \mathrm{~g}, 100 \mathrm{mmol})$, and triethylene glycol dimethyl ether (TEGDME) (30 mL) were added into Schlenk tube and the 10 mixture was stirred under the argon atmosphere at $180{ }^{\circ} \mathrm{C}$ for 24 h. The reaction mixture was cooled to room temperature, filtered and poured into $250 \mathrm{~mL}$ of ice cold water. The brown precipitate was collected by filtration. The product was purified by recrystallization from ethyl acetate to afford yellowish crystalline 15 solid $(1.83 \mathrm{~g}, 60 \%$ yield $):\left(\mathrm{mp}=170{ }^{\circ} \mathrm{C}\right.$; lit. $\left.172-173{ }^{\circ} \mathrm{C}\right){ }^{29} .{ }^{1} \mathrm{H}$ NMR $\left(400 \mathrm{MHz}, \mathrm{CDCl}_{3}\right) \delta=7.54-7.36(\mathrm{~m}, 2 \mathrm{H}), 7.31-7.18$ (m, $2 \mathrm{H}), 7.18-7.07(\mathrm{~m}, 2 \mathrm{H}), 6.96(\mathrm{dd}, \mathrm{J}=2.1,7.3 \mathrm{~Hz}, 4 \mathrm{H})$, $6.32(\mathrm{~d}, \mathrm{~J}=7.5 \mathrm{~Hz}, 2 \mathrm{H}), 4.03(\mathrm{~s}, 3 \mathrm{H}) \cdot{ }^{13} \mathrm{C} \mathrm{NMR}(100 \mathrm{MHz}$, $\left.\mathrm{CDCl}_{3}\right) \delta=55.6,115.7,116.3,118.9,122.6,126.7,127.4,132.1$, $20132.6,144.2,159.1$

Synthesis of 3-bromo-10-(4-methoxyphenyl)-10Hphenothiazine (7): 4-Phenothiazine-10-yl-anisole (2 g, $10 \mathrm{mmol})$ was added into $250 \mathrm{~mL}$ two necked round bottom flask containing chloroform ( $100 \mathrm{~mL}$ ). After purging the reaction 25 mixture with argon for half an hour, N-bromosuccinimide (1.28, $12 \mathrm{mmol}$ ) was added and the reaction mixture stirred for $12 \mathrm{~h}$ at room temperature. The reaction mixture was poured into $250 \mathrm{~mL}$ of ice cold water and extracted with dichloromethane. The dichloromethane solution was washed with water, separated and 30 dried over sodium sulfate. Removal of solvent on rotary evaporator afforded a crude product which was then chromatographed on neutral alumina with $2 \%$ ethyl acetate in petroleum ether as an eluent to obtain title compound ( $2.14 \mathrm{~g}$, $85 \%$ yield), as a green solid. ${ }^{1} \mathrm{H} \mathrm{NMR}\left(400 \mathrm{MHz}, \mathrm{CDCl}_{3}\right) \delta=$ 357.43 - $7.22(\mathrm{~m}, 2 \mathrm{H}), 7.22$ - $7.07(\mathrm{~m}, 3 \mathrm{H}), 7.07$ - $6.75(\mathrm{~m}, 4 \mathrm{H})$, $6.21(\mathrm{~d}, \mathrm{~J}=8.3 \mathrm{~Hz}, 1 \mathrm{H}), 6.05(\mathrm{dd}, \mathrm{J}=5.6,8.8 \mathrm{~Hz}, 1 \mathrm{H}), 3.92(\mathrm{~s}$, $3 \mathrm{H}){ }^{13} \mathrm{C} \mathrm{NMR}\left(100 \mathrm{MHz}, \mathrm{CDCl}_{3}\right) \delta=159.4,158.9,132.0,129.6$, 128.7, 126.9, 122.6, 116.9, 116.0, 55.6.

Synthesis of 10-(4-methoxyphenyl)-3-(4, 4, 5, 5-tetramethyl-1, ${ }_{40}$ 3, 2-dioxaborolan-2-yl)-10H-phenothiazine (8):

3-Bromo-10-(4-methoxyphenyl)-10H-phenothiazine (2 g, 1 mmol), bis(pinacolato)diboron (1.59 g, $1.2 \mathrm{mmol}), \mathrm{PdCl}_{2}(\mathrm{dppf})$ $(383 \mathrm{mg}, 0.1 \mathrm{mmol})$ and potassium acetate $(1.5 \mathrm{~g}, 3 \mathrm{mmol})$ were added into Schlenk tube under argon flow and then evacuated for 45 half an hour. Under an argon flow anhydrous dioxane $(25 \mathrm{~mL})$ was added to the reaction mixture. The solution was first stirred for $30 \mathrm{~min}$ at room temperature, and then at $80{ }^{\circ} \mathrm{C}$ for $24 \mathrm{~h}$. The reaction mixture was quenched by addition of ice-cold water $(250$ $\mathrm{mL})$ and then extracted with dichloromethane $(250 \mathrm{~mL})$. The 50 dichloromethane solution was washed with water, dried over anhydrous sodium sulfate and filtered. Removal of solvent on rotary evaporator afforded a crude product which was chromatographed on neutral alumina with $2 \%$ dichloromethane in petroleum ether as an eluent to obtain title compound $(1.21 \mathrm{~g}$, ${ }_{55} 68 \%$ yield), as a green solid. ${ }^{1} \mathrm{H} \mathrm{NMR}\left(400 \mathrm{MHz}, \mathrm{CDCl}_{3}\right) \delta=$ 7.42 (d, J = 1.4 Hz, $1 \mathrm{H}), 7.35-$
7.19 (m, $3 \mathrm{H}), 7.19-7.05$ (m, $2 \mathrm{H}), 6.97$ (d, J = 9.1 Hz, $1 \mathrm{H})$, $6.80(\mathrm{~d}, \mathrm{~J}=3.8 \mathrm{~Hz}, 2 \mathrm{H}), 6.14(\mathrm{~d}, \mathrm{~J}=8.0 \mathrm{~Hz}, 2 \mathrm{H}), 3.91(\mathrm{~s}, 3 \mathrm{H})$, $1.37-1.20(\mathrm{~m}, 12 \mathrm{H}){ }^{13} \mathrm{C} \mathrm{NMR}\left(100 \mathrm{MHz}, \mathrm{CDCl}_{3}\right) \delta=159.2$, 60 133.7, 132.9, 131.9, 126.6, 123.0, 122.5, 122.0, 115.3, 83.5, 55.5, 24.7.

Synthesis of 1,3,6,8-tetrakis(10-(4-methoxyphenyl)-10Hphenothiazin-3-yl)pyrene (PY-PH): 1,3,6,8-Tetrabromopyrene (0.5 g, $1 \mathrm{mmol})$, 10-(4-methoxyphenyl)-3-(4,4,5,5-tetramethyl65 1,3,2-dioxaborolan-2-yl)-10H-phenothiazine (2.49 g, $6 \mathrm{mmol}$ ), $2 \mathrm{M}$ aqueous $\mathrm{K}_{2} \mathrm{CO}_{3}(5 \mathrm{~mL})$ and $\mathrm{Pd}\left(\mathrm{PPh}_{3}\right)_{4}(0.111 \mathrm{~g}, 0.1 \mathrm{mmol})$ were added in Shlenck flask under argon flow. The flask was evacuated and refilled with argon three times and then anhydrous THF ( $25 \mathrm{~mL}$ ) was added into the flask and reaction mixture was 70 stirred at $80{ }^{\circ} \mathrm{C}$ for $48 \mathrm{~h}$. The reaction mixture was extracted with dichloromethane $(250 \mathrm{~mL})$ and washed with water $(500 \mathrm{~mL})$ and dried over anhydrous sodium sulphate. Removal of solvent on rotary evaporator afforded a crude product which was then purified using silica gel column chromatography with 4\% 75 dichloromethane in petroleum ether as an eluent to obtain title compound PY-PH (0.819 g, 60\% yield), as a yellow solid. ${ }^{1} \mathrm{H}$ NMR $\left(400 \mathrm{MHz}, \mathrm{CDCl}_{3}\right) \delta=8.13(\mathrm{~s}, 4 \mathrm{H}), 7.85$ (s, $\left.2 \mathrm{H}\right), 7.53-$ $7.23(\mathrm{~m}, 14 \mathrm{H}), 7.22$ - $6.95(\mathrm{~m}, 16 \mathrm{H}), 6.95$ - $6.71(\mathrm{~m}, 7 \mathrm{H}), 6.44$ $6.13(\mathrm{~m}, 8 \mathrm{H}), 3.94(\mathrm{~s}, 12 \mathrm{H}){ }^{13} \mathrm{C} \mathrm{NMR}\left(100 \mathrm{MHz}, \mathrm{CDCl}_{3}\right) \delta=$ $80159.3,143.9,44.5,135.9,135.0,133.3,132.3,128.5,126.8$, 125.1, 122.4, 119.6, 115.7, 55.6- MALDI-TOF: calculated 1415,04. found 1415.37

\section{OLED Device Fabrication:}

OLED devices were fabricated using PY-CA and PY-PH active 85 emitting layer for evaluating the electroluminescent (EL) performance. The OLED device configuration glass/ITO/PEDOT: PSS/PY-CA or PY-PH/TPBi/Ca/Ag was used. Patterned ITO glass substrates were routinely cleaned by detergent and deionized water, then blown dry by nitrogen gas 90 and kept in a $110{ }^{\circ} \mathrm{C}$ oven for $3 \mathrm{~h}$ before a $25 \mathrm{~min}$ ultra-violet ozone $\left(\mathrm{UVO}_{3}\right)$ surface treatment. Filtered poly (3, 4ethylenedioxythiophene) polystyrene sulfonate (PEDOT: PSS) solution was spin-coated on the patterned ITO glass substrates and they were baked at $140{ }^{\circ} \mathrm{C}$ for $20 \mathrm{~min}$. The thickness of the ${ }_{5}$ PEDOT: PSS films were controlled to $150 \mathrm{~nm}$. Then PY-CA and PY-PH solutions prepared in chloroform were separately spincoated on the individual PEDOT: PSS coated ITO glass substrates. They were baked at $70{ }^{\circ} \mathrm{C}$ for $20 \mathrm{~min}$. The thickness of both PY-CA and PY-PH films were controlled to $20 \mathrm{~nm}$. All the 100 spin-coat processes were performed in nitrogen glove box environment. Both the PY-CA and PY-PH coated substrates were then loaded into a thermal evaporation chamber at vacuum pressure of below $3 \times 10^{-6}$ Torr. $20 \mathrm{~nm}$ of 2,2 ', 2"-(1, 3, 5benzinetriyl)-tris (1-phenyl-1-H-benzimidazole) (TPBI), $20 \mathrm{~nm}$ of 105 calcium (Ca) and $100 \mathrm{~nm}$ of silver $(\mathrm{Ag})$ were coated on the substrates. With the completion of the device, EL measurements were carried out. The EL emission spectra were measured using PR650 CCD camera with a computer controller power supply The voltage-current-brightness (I-V-B) characteristics and the ${ }_{110}$ C.I.E. coordinates were also measured. The current and power efficiencies were calculated from the I-V-B data of the devices. 


\section{Cite this: DOI: $10.1039 / \mathrm{c0xx00000x}$}

ARTICLE TYPE

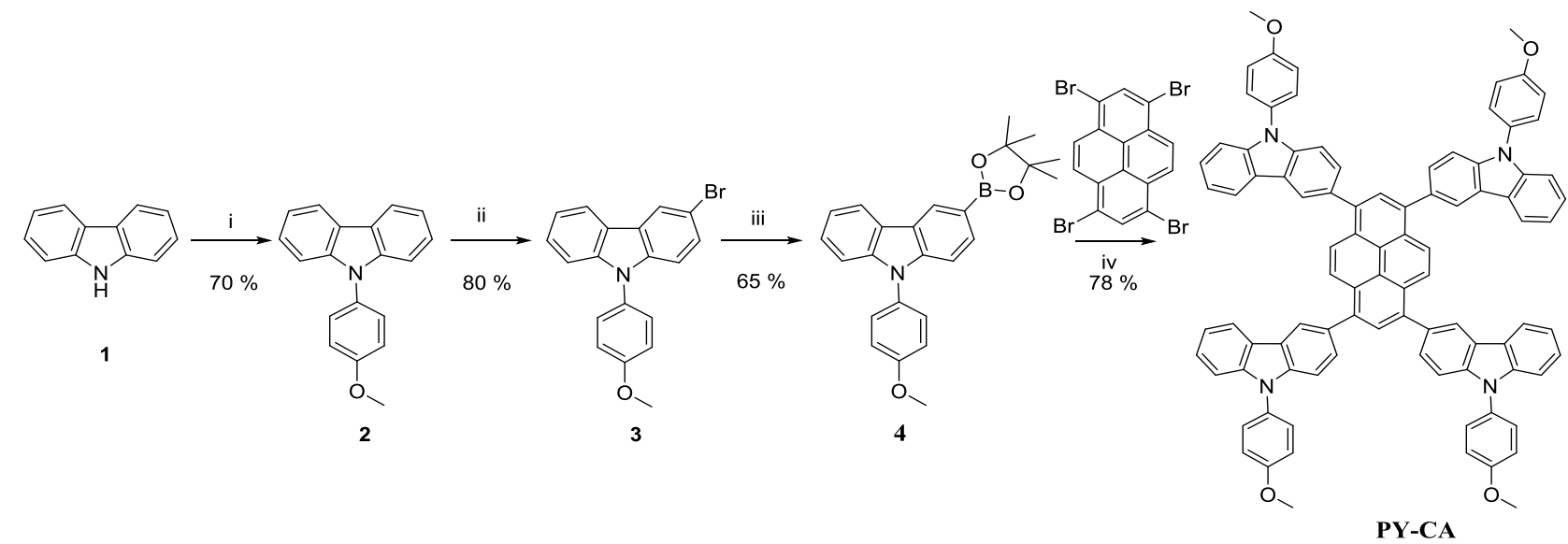

Scheme-1

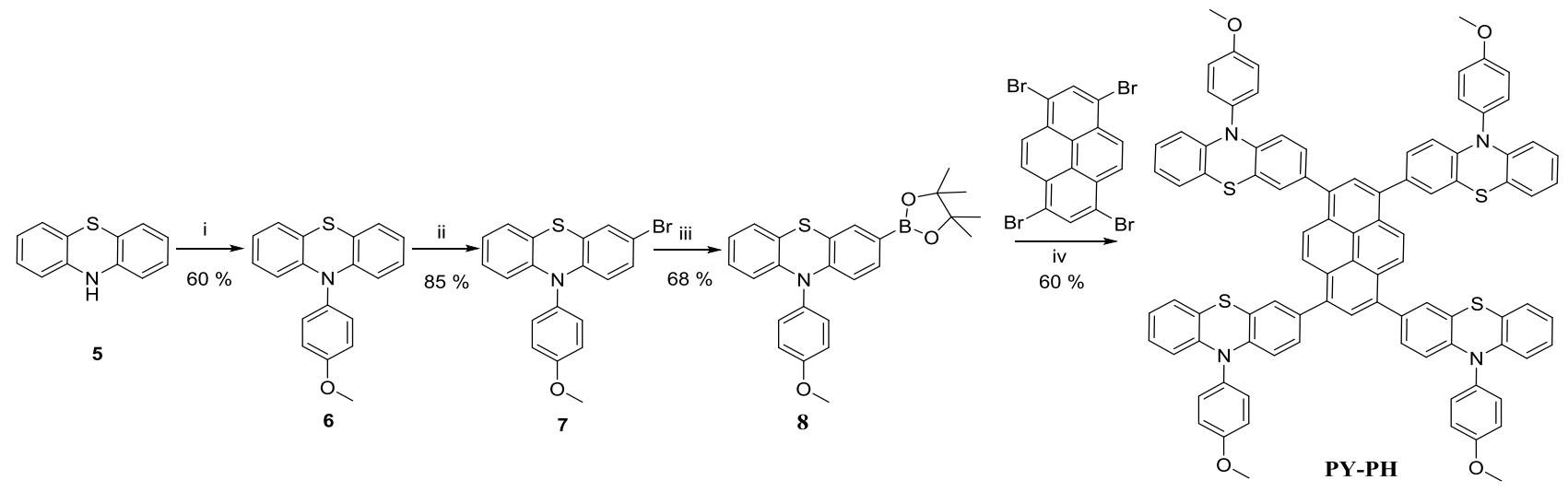

Scheme-2

Reagents:- (i) 4-Iodoanisole, DMSO, $\mathrm{Cu}, \mathrm{K}_{2} \mathrm{CO}_{3}, 180^{\circ} \mathrm{C}, 24 \mathrm{~h}$ (ii) $\mathrm{NBS}, \mathrm{CHCl}_{3}$, R.T. 12h. (iii) Bis (pinacolato) diboron, $\mathrm{Pd}$ (dppf) $\mathrm{Cl}_{2}$. $\mathrm{KOAc}, 80^{\circ} \mathrm{C}, 24 \mathrm{~h}$. (IV) $\mathrm{Pd}\left(\mathrm{PPh}_{3}\right)_{4}, \mathrm{~K}_{2} \mathrm{CO}_{3}(2 \mathrm{M})$, THF, $80^{\circ} \mathrm{C}, 48 \mathrm{~h}$.

\section{${ }_{10}$ Results and Discussion}

In this work, two different conjugated segments viz carbazole and phenothiazine were selected for attachment to the central pyrene chromophore. In order to induce the solution processibility, a methoxyphenyl group was attached to both the carbazole and 15 phenothiazine. First, commercially available compounds viz, carbazole (1) and phenothiazine (5) were converted to $9 \mathrm{H}-$ carbazole-9-(4-methoxyphenyl) (2) and 10-(4-methoxyphenyl)$10 \mathrm{H}$-phenothiazine (6), respectively in $70 \%$ and $60 \%$ yield via Buchwald coupling using 4-iodoanisole. Compound 2 and 6 were 20 then converted to their monobromo derivatives viz 3-bromo-9-(4methoxyphenyl)-9H-carbazole (3) and 3-bromo-10-(4methoxyphenyl)-10H-phenothiazine (7) using standard bromination conditions. Subsequent transformation of mono bromo compounds (3) and (7) to their respective bisboronic ester 25 analogs 9-(4-methoxyphenyl)-3-(4,4,5,5-tetramethyl-1,3,2dioxaborolan-2-yl)-9H-carbazole (4) and 10-(4-methoxyphenyl)-
3-(4,4,5,5-tetramethyl-1,3,2-dioxaborolan-2-yl)-10H-

phenothiazine (8) was carried out using bis(pinacolato)diboron reagent. The target compounds 1, 3, 6, 8-tetrakis(9-(430 methoxyphenyl)-9H-carbazol-3-yl)pyrene (PY-CA) and 1,3,6,8tetrakis(10-(4-methoxyphenyl)-10H-phenothiazin-3-yl)pyrene

(PY-PH) were prepared in $78 \%$ and $60 \%$ yield via classical Suzuki coupling conditions using 1, 3, 6, 8-tetrabromopyrene and monoboronic ester analogs (4) and (8) respectively. Syntheses of 35 both final pyrene compounds are shown in Scheme 1 and Scheme 2 . Both the derivatives were readily soluble in common organic solvents such as dichloromethane, chloroform, toluene, tetrahydrafuan, etc. This allowed purification of these compounds by column chromatography. The purity of all the synthesized 40 precursors as well as final semiconductors were confirmed by ${ }^{1} \mathrm{H}$ NMR, ${ }^{13} \mathrm{C}$ NMR and MALDI-TOF spectroscopy (see all the data in Supporting Information). The optical properties of PY-CA and PY-PH compounds were characterized in solution (chloroform) 
by both UV-vis absorption (UV) and photoluminescence (PL) spectroscopy (Figure 1). UV-vis spectra of both compounds exhibit two absorption peaks respectively at shorter and longer wavelengths. The absorption in the $300 \mathrm{~nm}$ to $500 \mathrm{~nm}$ region 5 clearly indicates the wide band gap nature of the compounds. PYCA exhibits two absorbance peaks at $339 \mathrm{~nm}$ and $400 \mathrm{~nm}$ whereas PY-PH showed peaks at $340 \mathrm{~nm}$ and $450 \mathrm{~nm}$, respectively. The near-identical peaks at $339 \mathrm{~nm}$ and $340 \mathrm{~nm}$ are the signature peaks for the central pyrene core and this is 10 comparable with absorbance of molecular pyrene $(338 \mathrm{~nm})$. Compared to the pyrene core, PY-CA and PY-PH exhibits the higher wavelength peaks at $400 \mathrm{~nm}$ and $450 \mathrm{~nm}$ respectively, which were arise from the enhanced conjugation between pyrene core and the attached carbazole/phenothiazine moiety. The $50 \mathrm{~nm}$ 15 red shift in PY-PH compared to PY-CA is due to the more extended conjugation length of phenothiazine than carbazole. Both compounds show red shift of about 60 and $100 \mathrm{~nm}$, respectively, in their absorption maxima compared to the base pyrene compound in solution state. The solution of PY-CA and ${ }_{20}$ PY-PH under UV-lamp shows deep sky blue and green emission (see Supporting Information). The peaks of the PL spectra of PYCA and PY-PH compounds were recorded at $450 \mathrm{~nm}$ and 500 $\mathrm{nm}$, respectively. The observed PL maxima are $50 \mathrm{~nm}$ and 100 $\mathrm{nm}$ red shifted compared to the pyrene photoluminescence 25 spectra (PL max $393 \mathrm{~nm}$ ).
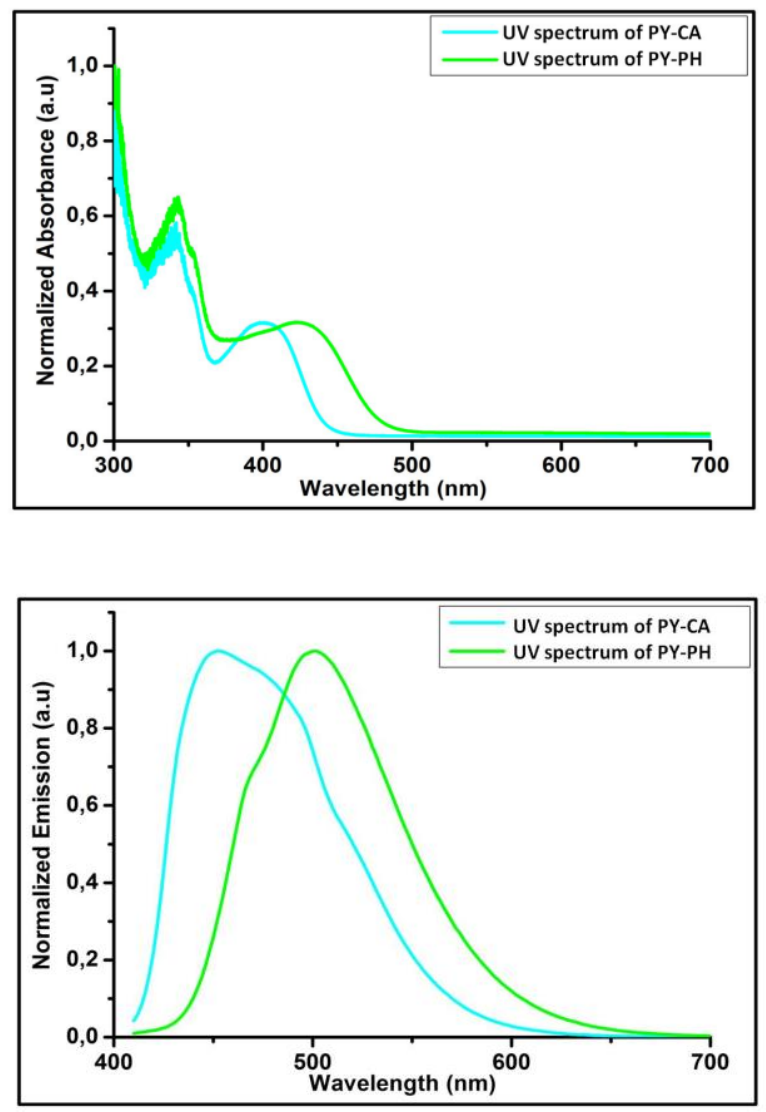

Figure 1. UV-vis absorption (upper) and photoluminiscence (lower) spectra of PY-CA and PY-PH compounds in chloroform
30 solution $\left(1 \times 10^{-4} \mathrm{M}\right)$. PL was measured at the $370 \mathrm{~nm}$ excitation wavalenegth.

The thin film of PY-PH and PY-CA were spin coated on the separate quartz substrates and were measured by UV-vis and PL spectroscopy, which is shown in Figure 2. In the solid state, PY${ }_{35}$ CA exhibits absorbance maxima at $425 \mathrm{~nm}$ whereas PY-PH showed peaks at $450 \mathrm{~nm}$, respectively. The value of the solid PYCA film is $25 \mathrm{~nm}$ red shifted compared to the solution measurement. Thin film PL measurement of PY-CA and PY-PH showed PL maxima at $485 \mathrm{~nm}$ and $520 \mathrm{~nm}$ respectively. The 40 optical band gap of these materials were measured by using spin coated thin films of PY-CA and PY-PH compounds from chloroform solution directly on ITO coated glass .The thin film optical data on ITO coated glass for PY-CA and PY-PH are shown in Figure 3. The optical band gap light absorption onset 45 was determined by extrapolating the steepest slope to the intersection of the absorption baseline (substrate). The band gap for PY-CA and PY-PH are $2.67 \mathrm{eV}$ and $2.50 \mathrm{eV}$, respectively. The observed optical band gaps are in a good agreement with our earlier reported thienothiophene substituted pyrene Py-TtC9 (2.44 $50 \mathrm{eV}){ }^{24}$ and naphthalene substituted pyrene PY-1 $(2.83 \mathrm{eV})^{25}$ analogous compounds.
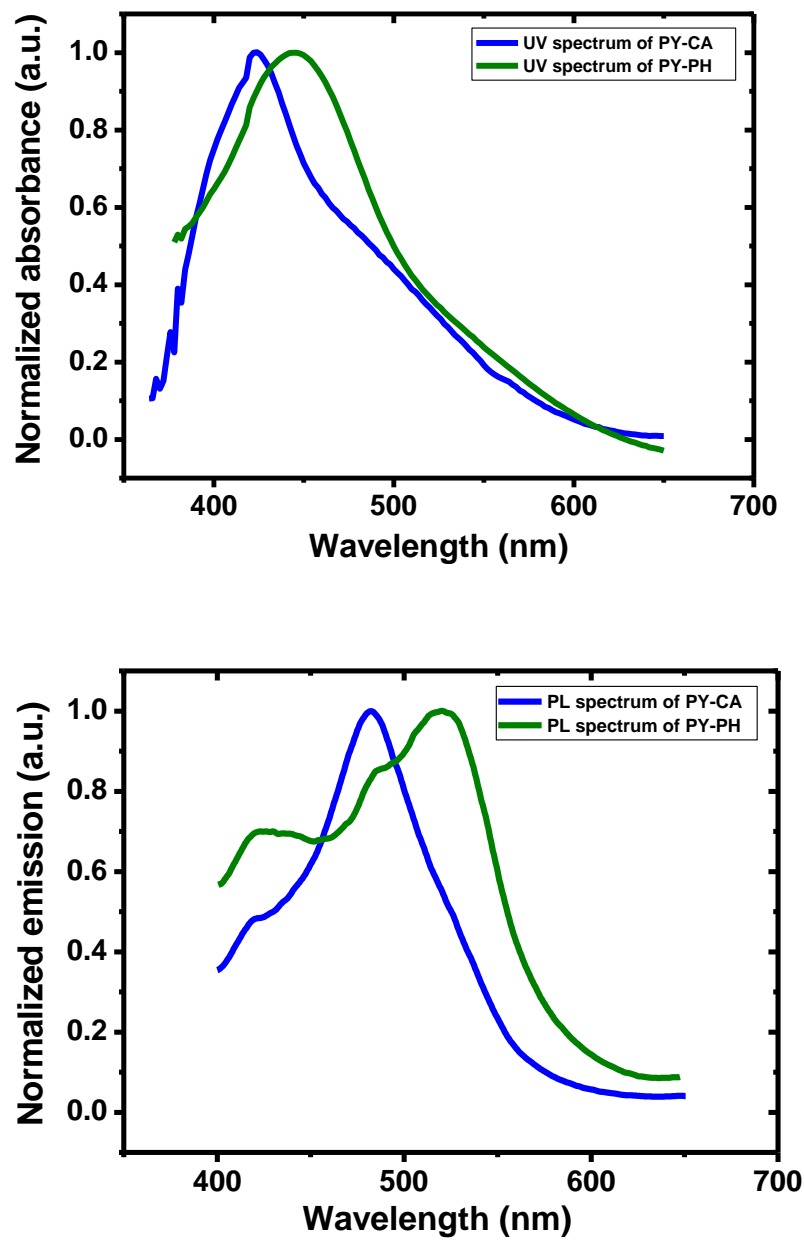

Figure 2. UV-vis absorption (upper) and photoluminiscence 55 (lower) spectra of PY-CA and PY-PH compounds in thin film. 
The higher band gap value of PY-CA and PY-PH is a clear sign of the wide band gap blue-green emitters. The energy levels of PY-CA and PY-PH organic semiconductors were characterized by the photoelectron spectroscopy in air (PESA) as shown in 5 Figure 4. Thin films of PY-CA and PY-PH were deposited on the ITO coated glass by spin coating, which were used for the determination the ionization potential. The photoelectron yield ratio was measured with respect to the applied UV-energy. The onset point or slope across this graph gave the HOMO value of 10 these materials. $^{30,31}$ The HOMO value for the PY-CA and PYPH are $5.48 \mathrm{eV}$ and $5.40 \mathrm{eV}$, as recorded by PESA. The lower HOMO values of PY-CA and PY-PH are significant for making air stable organic electronic devices. The higher HOMO of PYPH compared to PY-CA is again attributed to the extended 15 conjugated moiety and electron rich sulfur of phenothiazine. This observation is in good agreement with optical red shift and optical band gap measured for PY-PH.
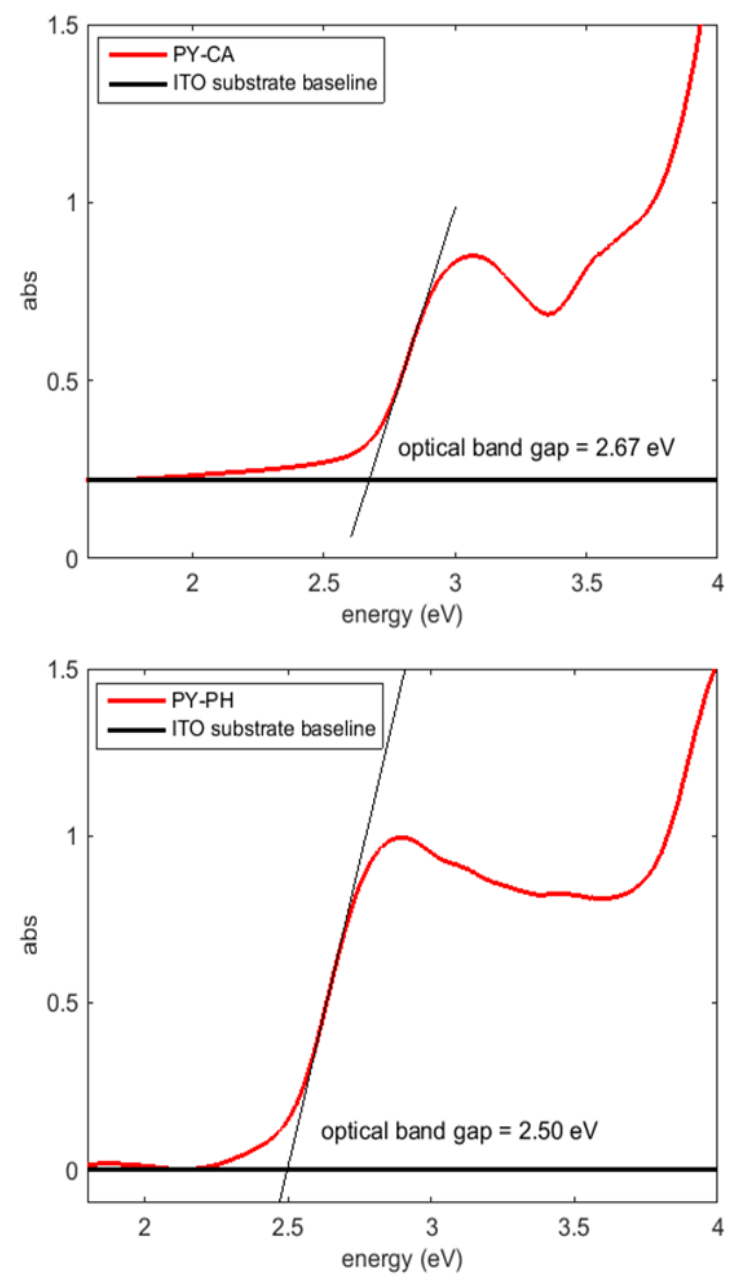

Figure 3. Optical band gap calculated using a thin film of PYCA (upper) and PY-PH (lower) spin coated on the ITO coated glass substrates.

${ }_{25}$ Density Functional Theory (DFT) ${ }^{32}$ calculations were performed to compute molecular structures, the energies of frontier orbitals and their localization as well as absorption and photoluminescence (PL) spectra. The B3LYP ${ }^{33}$ and CAMB3LYP ${ }^{34}$ exchange-correlations functionals were used with the ${ }_{30} 6-31 \mathrm{~g}(\mathrm{~d}, \mathrm{p})$ basis set. These B3LYP and CAM- B3LYP correlations functionals were used because B3LYP provides more reliable HOMO (highest occupied molecular orbital) and LUMO (lowest unoccupied molecular orbital) energies which can be compared to the measured redox levels, while the range-separated ${ }_{35}$ CAM-B3LYP is preferred for optical properties involving transitions with significant degree of charge transfer.

(a)

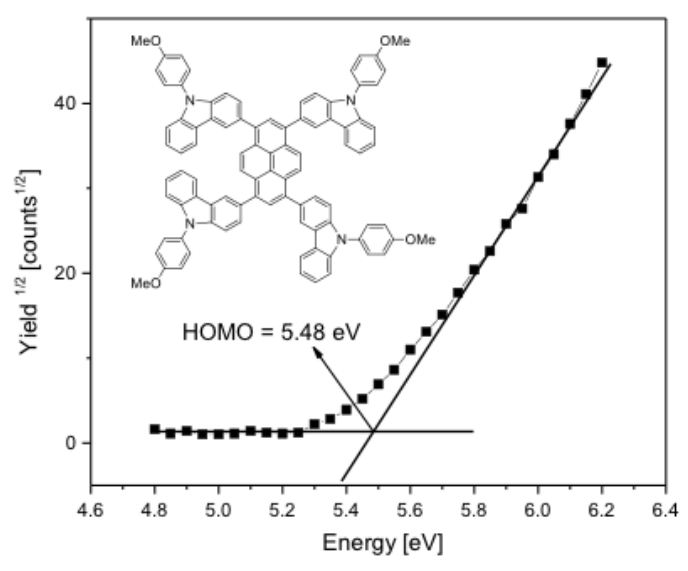

(b)

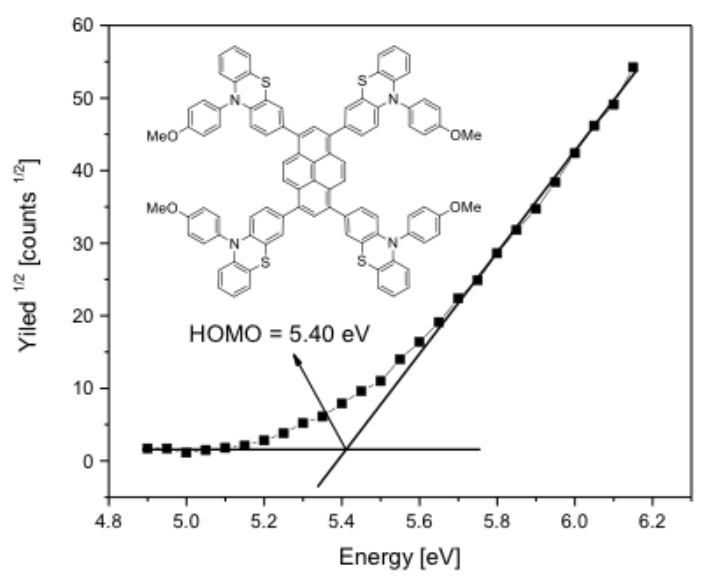

${ }^{40}$ Figure 4 Photoelectro spectroscopy in air (PESA) analysis of compound PY-CA (a) and PY-PH (b) compounds in thin film.

The absorption and PL spectra were computed with time45 dependent DFT (TD-DFT). ${ }^{35}$ The PL spectra were computed by optimizing the first excited state. The calculations were performed in chloroform with the PCM (polarizable continuum model) ${ }^{36}$ model of the solvent. All calculations were performed using Gaussian 09. ${ }^{37}$ The HOMO and LUMO of PY-PH and ${ }_{50}$ PY-CA are shown in Figure 5 and Figure 6, respectively. In both comopunds, the HOMO is more delocalized than the LUMO and has appreciable amplitude on the phenothiazine and carbazole moieties, respectively, while the LUMO is more localized on the 
central fused pyrene core and partially on the fused backbone of the PH or CA units. This also means that there is an appreciable degree of charge transfer in the transition responsible for the first peak in the absorption and PL spectrum (which we confirmed is 5 mostly due to HOMO $\rightarrow$ LUMO) which calls for the use of a range-separated hybrid functional in the analysis of optical properties. ${ }^{38,39}$ The calculated HOMO and LUMO energies of PY-CA are $-4.82 \mathrm{eV}$ and $-1.63 \mathrm{eV}$ whereas for PY-PH, they are $4.79 \mathrm{eV}$ and $-1.79 \mathrm{eV}$, respectively. The higher HOMO value for

${ }_{10}$ PY-PH compared to PY-CA is related to the longer conjugation length of phenothiazine over carbazole. The HOMO-LUMO band gap for PY-CA and PY-PH was calculated to be $3.18 \mathrm{eV}$ and 3.0 $\mathrm{eV}$, respectively. The computed contraction of the band gap in PY-PH vs PY-CA of $0.18 \mathrm{eV}$ matches well with the 15 experimentally measured difference in optical band gaps of 0.17 $\mathrm{eV}$.

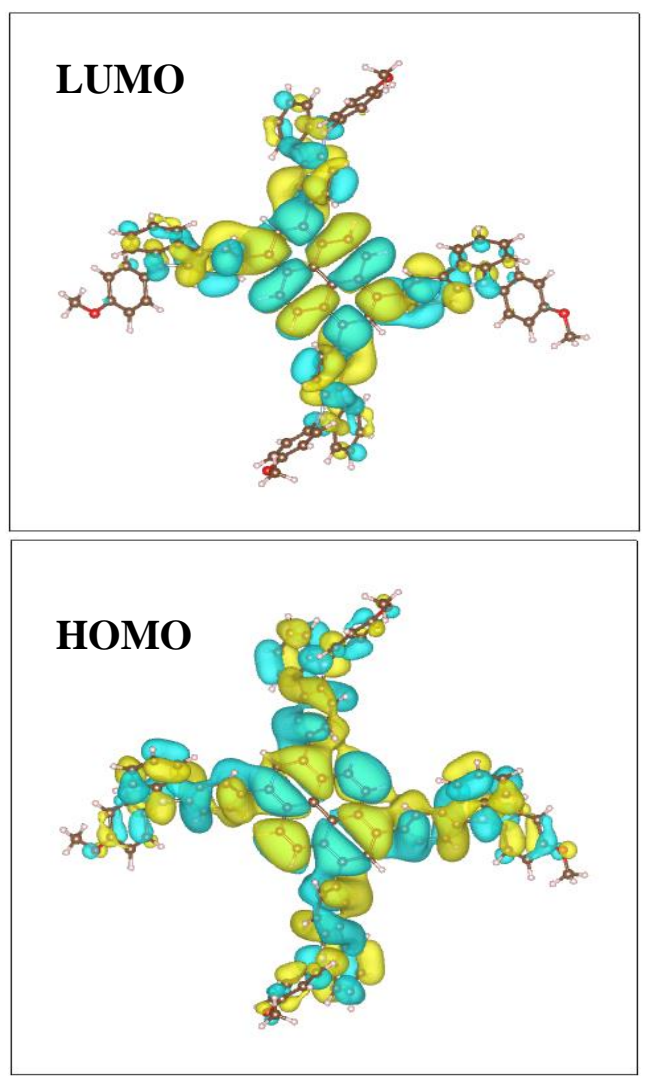

20

Figure 5. The electron density isocontours of HOMO and LUMO of PY-CA obtained at the CAM-B3LYP level (visualization of orbitals here and elsewhere by VESTA). ${ }^{41}$

25 The absorption peak maximum computed with CAMB3LYP/B3LYP is $379 / 437 \mathrm{~nm}$ for PY-CA and 389/471 nm for PY-PH. The absorption spectra are shown in the Supporting Information. The peaks computed using the two functionals therefore straddle the measured peaks at 400 and $450 \mathrm{~nm}$ of PY-

${ }_{30} \mathbf{C A}$ and PY-PH, respectively (vide infra). This is expected, as B3LYP is known to underestimate the excitation energy for large conjugated systems and CAM-B3LYP to often overestimate it. ${ }^{40}$ These calculations confirm the red shift of the peak with phenothiazine vs carbazole which is observed experimentally. 35 The red shift was also confirmed for PL: the computed PL peaks were 471 and $538 \mathrm{~nm}$ for PY-CA and PY-PH, respectively (CAM-B3LYP, see Supporting Information). In order to test the electroluminescent properties of PY-CA and PY-PH materials, we used them as an active emissive layer in OLED devices. 40

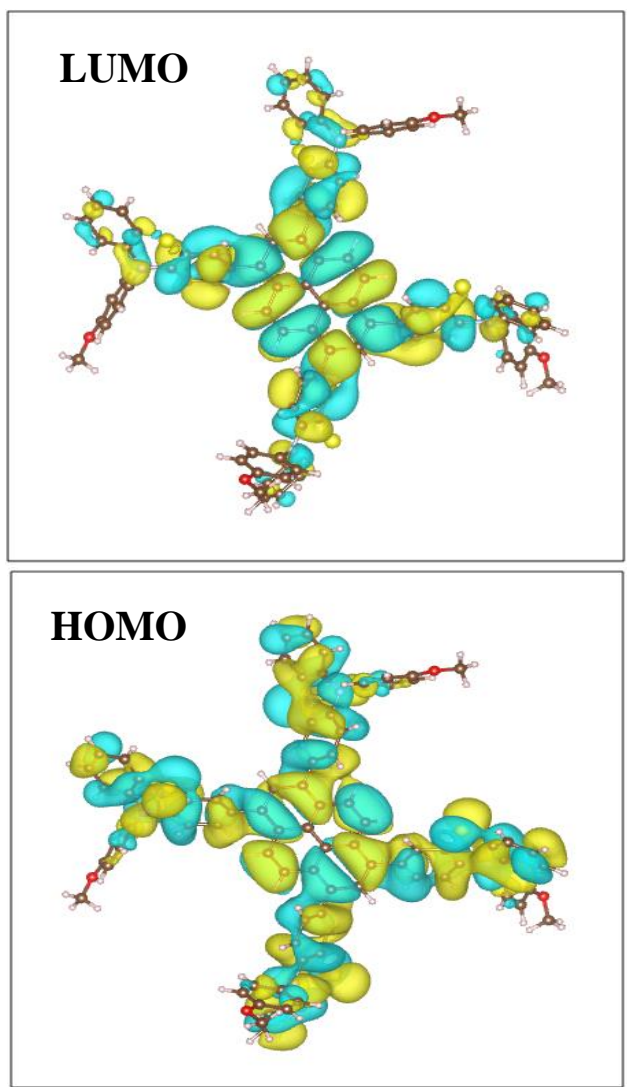

Figure 6. The electron density isocontours of HOMO and LUMO 45 of PY-PH obtained at the CAM-B3LYP level.

The device configurations of compounds PY-CA and PY-PH are ITO/PEDOT:PSS(50nm)/PY-CA $(50 \mathrm{~nm}) / \mathrm{TPBi}(20 \mathrm{~nm}) / \mathrm{Ca}(20$ $\mathrm{nm}) / \mathrm{Ag} \quad(100)$ and ITO/PEDOT:PSS(50nm)/PY-PH $\quad$ (50 $50 \mathrm{~nm}) / \mathrm{TPBi}(20 \mathrm{~nm}) / \mathrm{Ca}(20 \mathrm{~nm}) / \mathrm{Ag}(100)$ respectively (see Figure $7)$. ITO coated glass and calcium with silver act as anode and cathode respectively whereas 2,2',2"-(1,3,5-benzinetriyl)-tris(1phenyl-1-H-benzimidazole) (TPBI) is an electron transporting layer. When a potential is applied, holes are injected from anode 55 and electrons injected from the cathode respectively. Due to the recombination of holes and electrons in the active emissive layer, blue and green photon emission was observed in OLED devices. The observed electroluminescence (EL) was recorded as shown in Figure 7, while the EL performance data are given in Table 1. ${ }_{60}$ The PY-CA device has an EL maximum of $493 \mathrm{~nm}$ emission peak in the visible blue region with a full wave half maximum (FWHM) of $80 \mathrm{~nm}$ and CIE coordinates of 0.19 and 0.42 . While the PY-PH device has an EL maximum of $540 \mathrm{~nm}$ in the visible green region with a FWHM of $85 \mathrm{~nm}$ and CIE coordinates of ${ }_{65} 0.37$ and 0.59 . The PY-CA device shows turn on voltage $\left(\mathrm{V}_{\text {on }}\right)$, 
maximum current efficiency $\left(\mathrm{CE}_{\max }\right)$, maximum power efficiency $\left(\mathrm{PE}_{\max }\right)$, maximum brightness $\left(\mathrm{MB}_{\max }\right)$ of $3.3 \mathrm{~V}, 1.6 \mathrm{~cd} / \mathrm{A}, 1.5$ $\mathrm{lm} / \mathrm{W}$ and $2500 \mathrm{~cd} / \mathrm{m}^{2}$, respectively. Whereas the PY-PH device exhibits $\mathrm{V}_{\mathrm{on}}, \mathrm{CE}_{\max }, \mathrm{PE}_{\max }$ and $\mathrm{MB}_{\max }$ of $3.8 \mathrm{~V}, 1.1 \mathrm{~cd} / \mathrm{A}, 0.45$ $5 \mathrm{~lm} / \mathrm{W}$ and $2116 \mathrm{~cd} / \mathrm{m}^{2}$. The power efficiency of the PY-CA device is almost three times higher $(1.5 \mathrm{~lm} / \mathrm{W})$ than the PY-PH device $(0.45 \mathrm{~lm} / \mathrm{W})$. The CE and PE characteristic of the PY-CA and the PY-PH device is shown in Figure 8.

10
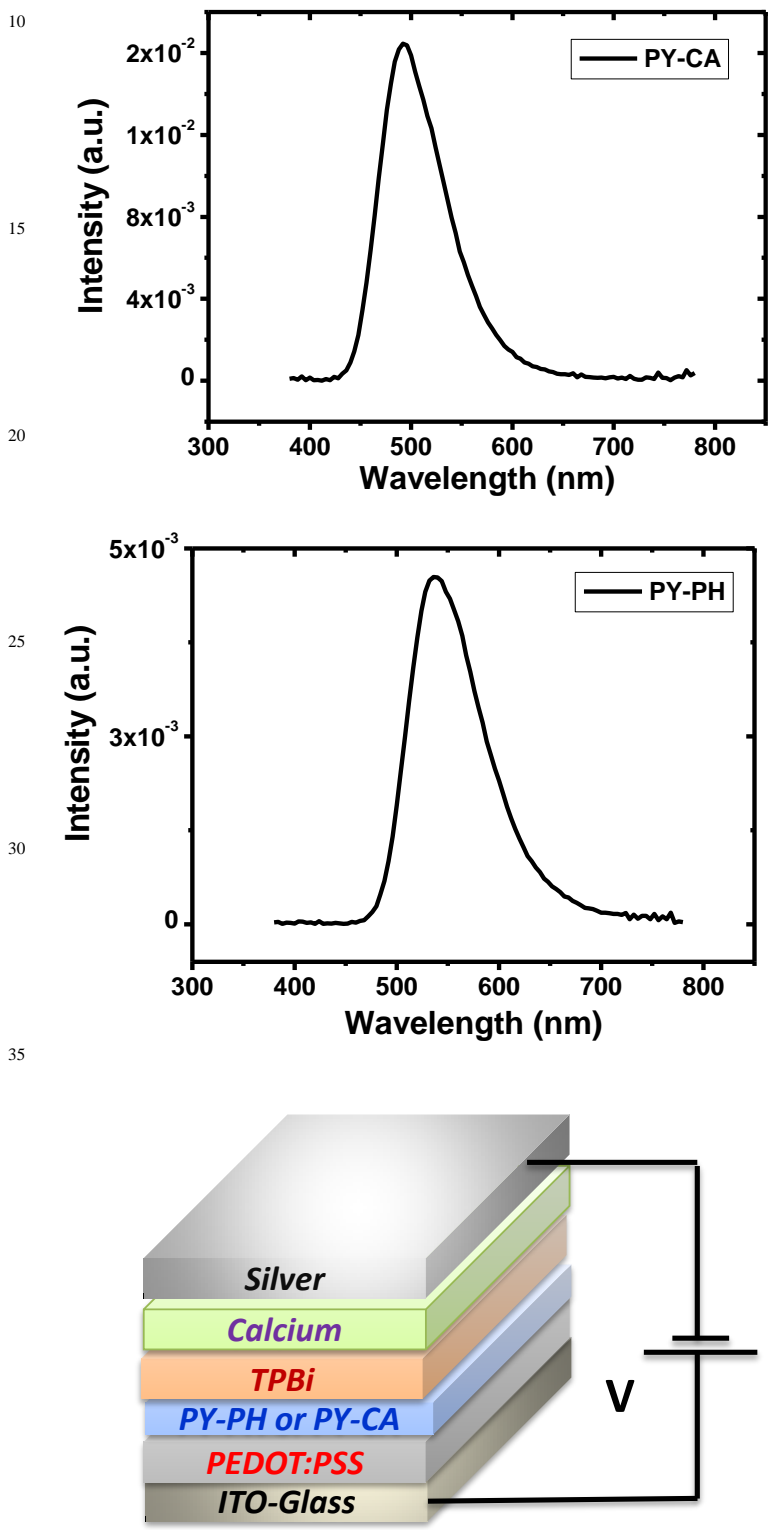

Figure 7. Carbazole substituted pyrene PY-CA (upper) and 40 phenothiazine substituted pyrene PY-PH (middle) based electroluminiscent spectrum and PY-CA or PY-PH light emitting layer deposited OLED device structure (lower).

As the voltage increase from $3 \mathrm{~V}$ to $4 \mathrm{~V}$, both the $\mathrm{CE}$ and $\mathrm{PE}$ of 45 the PY-CA device increase rapidly to the $\mathrm{CE}_{\max }$ and the $\mathrm{PE}_{\max }$ of $1.6 \mathrm{~cd} / \mathrm{A}$ and $1.5 \mathrm{~lm} / \mathrm{W}$ respectively. As the drive voltage further increases, the CE and PE curves of the PY-CA device roll-off less rapidly. However, the CE and PE of the PY-CA device still remain at higher than one-half of the $\mathrm{CE}_{\max }$ and $\mathrm{PE}_{\max }$ even as the ${ }_{50}$ drive voltage is increased from $4 \mathrm{~V}$ to $11 \mathrm{~V}$ and $7.5 \mathrm{~V}$, respectively. As the voltage increases from $3.8 \mathrm{~V}$ to around $8 \mathrm{~V}$, both the CE and PE of the PY-PH device increase gradually to the $\mathrm{CE}_{\max }$ and the $\mathrm{PE}_{\max }$ of $1.1 \mathrm{~cd} / \mathrm{A}$ and $0.45 \mathrm{~lm} / \mathrm{W}$, respectively. Unlike the case of the PY-CA device, the CE and PE curves of 55 the PY-PH device roll-off more rapidly, the $\mathrm{CE}$ and PE drop to one-half of the $\mathrm{CE}_{\max }$ and $\mathrm{PE}_{\max }$ when the drive voltage is increased from $8 \mathrm{~V}$ to $10 \mathrm{~V}$. The overall higher performance of PY-CA than PY-PH is attributed to the appropriate energy levels for hole injection, better charge transporting and carrier mobility. ${ }_{60}$ The observed OLED performances for both compounds are much better than our previously reported naphthalene substituted pyrene derivatives. ${ }^{25}$ The stable blue color output additionally proves that PY-CA has high prospective to be a blue emitter in OLED applications. The turn on voltage of $3.3 \mathrm{~V}$ also makes PY${ }_{65}$ CA based OLED device energy efficient.
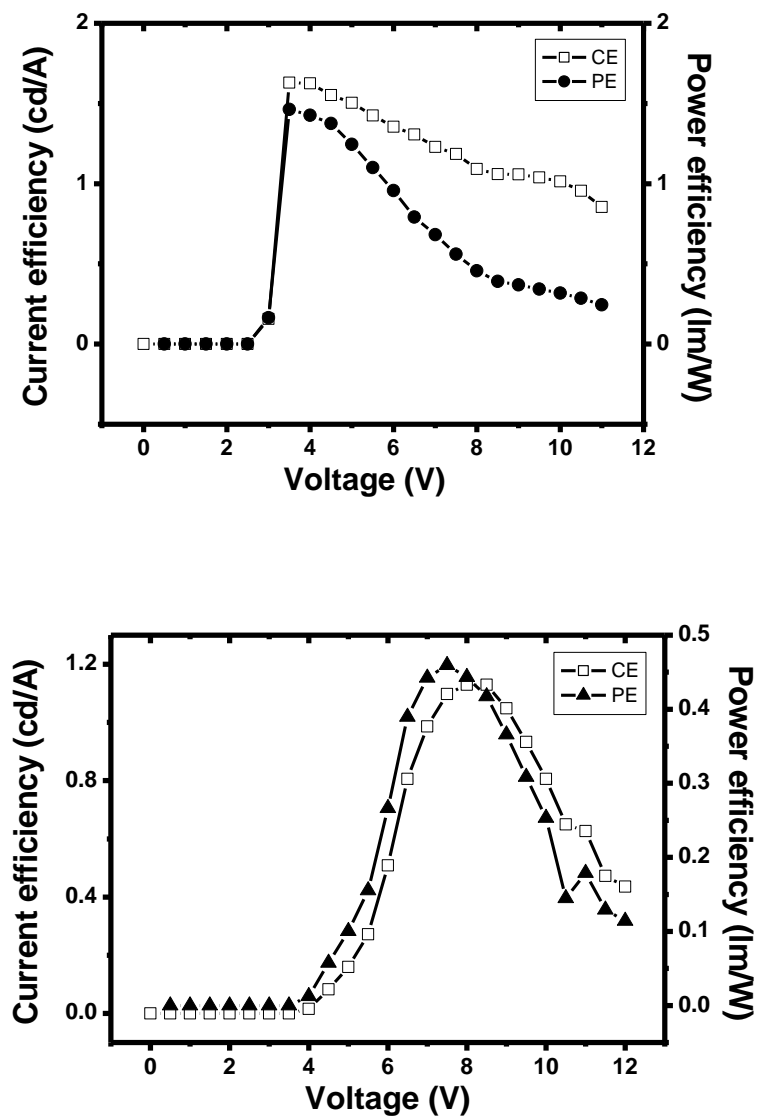

Figure 8. CE and PE characteristic of the PY-CA device (upper) and the PY-PH device (lower).

70 The morphological behavior of PY-CA and PY-PH active layer thin film was characterized by atomic force microscopy (AFM) as shown in Figure 9. The measured root mean square (RMS) roughness of film samples was $2.32 \mathrm{~nm}$ for PY-CA and $1.06 \mathrm{~nm}$ for PY-PH. The pristine ITO coated glass showed high surface 75 roughness with an RMS of $3.25 \mathrm{~nm}$. Smooth film morphology of 


\section{Cite this: DOI: $10.1039 / \mathrm{c0xx00000x}$}

Table1. Electroluminescent performance summary of PY-PH and PY-CA based OLED device

\begin{tabular}{|c|c|c|c|c|c|c|}
\hline Device & $\begin{array}{l}\text { Turn on } \\
\text { Voltage } \\
\text { (V) }\end{array}$ & $\begin{array}{c}\text { Current } \\
\text { Efficiency } \\
\text { (Cd/A) }\end{array}$ & $\begin{array}{l}\text { Power Efficiency } \\
(\operatorname{lm} / \mathbf{W})\end{array}$ & CIE & $\begin{array}{l}\text { Electroluminescent } \\
\text { Peak }(\mathbf{n m})\end{array}$ & $\begin{array}{l}\text { Max. Brightness } \\
(\mathrm{cd} / \mathrm{m} 2)\end{array}$ \\
\hline PY-CA & 3.3 & 1.6 & 1.5 & $(0.19,0.42)$ & 493 & 2500 \\
\hline PY-PH & 3.8 & 1.1 & 0.45 & $(0.37,0.59)$ & 540 & 2116 \\
\hline
\end{tabular}
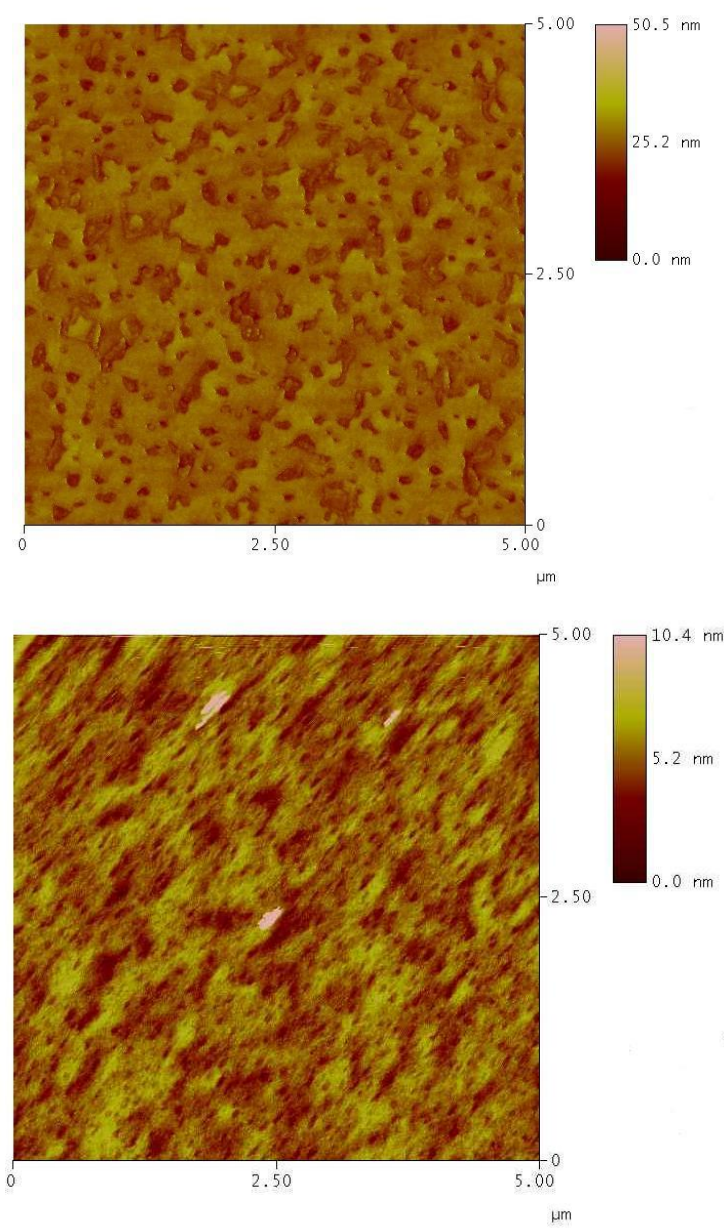

Figure 9. Atomic force microscope images of PY-CA (upper) and PY-PH (lower) spin coated thin film on ITO coated glass.

PY-PH film compared to PY-CA might be attributed to the 10 more bulky phenothiazine group compared to carbazole moiety. This is also one of the reasons why PY-CA exhibited better
OLED performance than PY-PH counterpart. The AFM images of PY-CA and PY-PH clearly demonstrated the amorphous nature of the thin film with complete coverage of microstructure 15 domains on the thin film. Thin film morphology plays crucial role for light emission in terms of transportation of holes and electrons in recombination zone.

\section{Conclusions}

20 In summary, we have successfully designed and synthesized a new solution processable 1, 3, 6, 8- tetrasubstituted pyrene based electroluminescent organic semiconductors namely PY-CA and PY-PH via Suzuki coupling. PY-CA and PY-PH exhibited wide UV-vis absorption starting in the region $300 \mathrm{~nm}$ to $500 \mathrm{~nm}$ with 25 an optical band gap of $2.67 \mathrm{eV}$ and $2.50 \mathrm{eV}$, respectively. The HOMO values of PY-CA and PY-PH thin films were determined using PESA and were found to be $5.48 \mathrm{eV}$ and $5.40 \mathrm{eV}$ respectively. PY-CA and PY-PH were used for OLED device applications and their electroluminescence properties were 30 studied. The turn on voltage for both the devices was calculated in the range of $3.3 \mathrm{~V}$ to $3.8 \mathrm{~V}$. PY-CA exhibited blue emission with electroluminescent peak at $493 \mathrm{~nm}$, maximum brightness around $2500 \mathrm{~cd} / \mathrm{m}^{2}$ and power efficiency of $1.5 \mathrm{~lm} / \mathrm{W}$ whereas PY-PH shows green emission with electroluminescent peak at ${ }_{35} 540 \mathrm{~nm}$, maximum brightness around $2116 \mathrm{~cd} / \mathrm{m}^{2}$ and power efficiency of $0.5 \mathrm{~lm} / \mathrm{W}$. The reported OLED data clearly indicate that this class of functional materials hold a great promise for designing future cost effective and efficient light emitting materials for OLED devices. Further enhancements are expected 40 to obtain improved performance with optimized molecular and device structure for OLED displays.

\section{Acknowledgements}

F. L. Wong, V. A. L. Roy is thankful to the Research Grants Council of the Hong Kong Special Administrative Region 45 (Project No. T23-713/11). PS thanks to Queensland University of 
Technology (QUT) and Australian Research Council (ARC) for financial support (FT130101337). S.M. thanks to the Ministry of Education of Singapore (AcRF grant). KF thanks the Australian Renewable Energy Agency for financial support.

\section{${ }_{5}$ Notes and references}

${ }^{a}$ Polymer Science and Engineering Division, CSIR-National Chemical Laboratory, Dr. Homi Bhabha Road, Pune 411008, India.

${ }^{b}$ Current Address: Department of Chemistry and Bioengineering, 10 Tampere University of Technology, P.O. Box 541, FI-33101 Tampere, Finland

${ }^{c}$ Center of Super Diamond and Advanced Films, and Department of Physics and Materials Science City, University of Hong Kong, Tat Chee 15 Avenue, Kowloon, Hong Kong

${ }^{d}$ CSIRO Energy Centre10 Murray Dwyer Circuit Mayfield West NSW 2304, Australia

${ }_{20}{ }^{e}$ Department of Mechanical Engineering Faculty of Engineering, National University of Singapore Block EA \#07-08, 9 Engineering Drive 1, Singapore 117576

${ }^{f}$ School of Chemistry, Physics and Mechanical Engineering, Queensland 25 University of Technology(QUT), Brisbane, Australia

$\dagger$ Electronic Supplementary Information (ESI) available: NMR, MALDITOF MS data of compounds $2,3,4,5,6,7,8$, PY-CA and PY-PH See DOI: $10.1039 / \mathrm{b} 000000 \mathrm{x}$

\section{References}

1. C. W. Tang, S. A. Vanslyke, Appl. Phys. Lett. 1987 , 51, 913

2. A. C. Grimsdale, K. L. Chan, R. E. Martin, P. G. Jokisz and A.

35 B. Holmes, Chem. Rev., 2009, 109, 897.

3 L. S. Hung, C.H. Chen, Mat. Sci. Eng., R 2002, 39 , 143.

4. J. Kido and Y. Okamoto, Chem. Rev., 2002, 102, 2357.

5. H.Uoyama, K. Goushi, K.Shizu, H. Nomura, C. Adachi, Nature, 2012, 492, 234.

40 6. Y. H. Kim, H. C. Jeong, S. H. Kim, K. Yang, S. K. Kwon, $A d v$. Funct. Mater. 2005, 15, 1799.

7. Z. J. Zhao, S. M. Chen, J. W. Y. Lam, P. Lu, Y. C. Zhong, K. S. Wong, H. S. Kwok, B. Z. Tang, Chem. Commun. 2010, 46, 2221.

45 8. X. Kong, A. P. Kulkarni, S. A. Jenekhe. Macromolecules 2003, 36, 8992.

9. K. R. J. Thomas, M Velusamy, J. T. Lin, Y. T. Tao, H. Chuen, Adv. Funct. Mater. 2004, 14, 387-392.

10. Organic Light-Emitting Devices: Synthesis, Properties, and

50 Applications, ed. K. Muellen and U. Scherf, Wiley-VCH, 2006, vol. 978.

11. Z. Ma, P. Sonar and Z. K. Chen, Curr. Org. Chem., 2011, 14, 2034.

12. J. N. Moorthy, P. Natarajin, P. Venkatakrishnan, D. F. Huang $55 \quad$ and T. J. Chow, Org. Lett., 2007, 9, 5215.

13. M. Y. Lo, C. G. Zhen, M. Lauters, G. E. Jabbour, A. Sellinger, J. Am. Chem. Soc., 2007, 129, 5808.

14. R. D. Xia, W. Y. Lai, P. A Levermore, W. Huang, D. D. C. Bradley, Adv. Funct. Mater., 2009, 19, 2844.
60 15. Z. J. Zhao, J. H. Li, X. P. Chen, X. M. Wang, P. Lu, Y. Yang, J. Org. Chem., 2009, 74, 383.

16. H. J. Zhang, Y. Wang, K. Z. Shao, Y. Q. Liu, S. Y. Chen, W. F. Qiu, X. B. Sun, T. Qi, Y. Q. Ma, G. Yu, Z. M. Su, D. B. Zhu, Chem. Commun., 2006, 755.

65 17. M. J. Sienkowska, J. M. Farrar, F. Zhang, S. Kusuma, P. A. Heiney and P. Kaszynski, J. Mater. Chem., 2007, 17, 1399.

18. F. Liu, W. Y. Lai, C. Tang, H. B. Wu, Q. Q. Chen, B. Peng, W. Wei, W. Huang and Y. Cao, Macromol. Rapid Commun., 2008, 29, 659.

70 19. Y. Sagara, T. Mutai, I. Yoshikawa and K. Araki, J. Am. Chem. Soc., 2007, 129, 1520.

20. N. J. Jeon, J. Lee, J. H. Noh, M. K. Nazeeruddin, M. Grätzel, S. Seok, J. Am. Chem. Soc. 2013, 135, 19087

21. J. B. Birks, Photophysics of Aromatic Molecules, Wiley-

75 Interscience, London, 1970.

22. J. R. Lackowicz, Principles of Fluorescence Spectroscopy, Kluwer Academic/Plenum Publishers, New York, 2 edn, 1999, pp. 595

23. M. T. Figueira-Duarte, K. Mullen. Chem. Rev. 2011, 111, 7260.

24. P. Sonar, M. S. Soh, Y. H. Cheng, J. T. Henssler, A. Sellinger, Org. Lett., 2010, 12, 3292.

25. J. K. Salunke, P. Sonar, F. L. Wong, V. A. L. Roy, C. S. Lee, P. P. Wadgaonkar, Phys. Chem. Chem. Phys., 2014, 16, 8523320.

26. S. J. Lee, J. S. Park, K.-J. Yoon, Y.-I. Kim, S.-H Jin, S. K. Kang, Y.-S. Gal, S. K., J. Y. Lee, J.-W. Kang, S-H. Lee, H.D. Park, J.-J. Kim Adv. Funct. Mater. 2008, 18, 3922-3930.

27. G. B. Bodedla, K. R. J. Thomas, S. Kumar, J.-H. Jou. C.-J. Li. $90 \quad R S C$ Adv., 2015, 5, 87416-87428.

28. A. Matoliukstyte, J.V. Grazulevicius, J.A. Reina, V. Jankauskas , E. Montrimas, Mater. Chem. Phys., 2006, 98, 324.

29. J. H. Huang, K. C. Lee ACS Appl. Mater. Interfaces 2014, 6, 95 7680-7685

30. J. Jasieniak, M. Califano, S. E. Watkins, ACS Nano, 2011, 5, 588

31. M. Onoda, K. Tada, H. Nakayama, J. Appl. Phys. 1999, 86, 1999.

100 32. W. Kohn, L. J. Sham, Phys Rev, 1965, 40, A1133.

33. A.D. Becke, J. Phys, Chem., 1993, 5648

34. T. Yanai, D. Tew, N. Handy, Chem. Phys. Lett., 2004, 393, 51.

35. M. A. L. Marques MAL, Annu. Rev. Phys. Chem., 2004, 55, 427.

36. J. Tomasi, B. Mennucci, R. Cammi, Chem. Rev., 2006, 105, 2999.

37. M. J. Frisch (2009) Gaussian 09. Gaussian Inc., Wallingford.

38. M. J. G. Peach, P. Benfield, T. Helgaker, D.J. Tozer, J. Chem. $110 \quad$ Phys. 2008, 128, 044118.

39. S. Manzhos, H. Segawa, K. Yamashita, Chem. Phys. Lett. 2013, 527, 51.

40. D. Jacquemin, V. Wathelet, E. A. Perpete, C. Adamo, J. Chem. Theory Comput., 2009, 5, 2420.

115 41. K. Momma, F. Izumi, J. Appl. Crystallogr., 2011, 44, 1272. 